\title{
230 PRANAYAMA: A DIVINE POWER IN SPORTS
}

Vinuta Muktamath, Umesh Muktamath, Basavaraj Ganiger University of Agricultural Sciences, Dharwad, Karnataka, India

10.1136/bjsm.2010.078725.230

In day to life stress became a big problem in our society, especially in sports. Though a top class sportsman is having scientific coaching and proper nutrition, still he is lacking in showing top class performance because of more stress. Stresses always hamper the performance of an individual in sports competitions. Pranayama is the fourth limb and meditation is the seventh limb of ashtanga yoga. Its full significance has to be properly understood and appreciated. It consists of two components, pran and ayama. Pran is introduced by Sri Yogendraj has bioenergy and ayama means control or discipline. The real meaning of pranayama, therefore, is control of bio-energy. Prana is an essential living activity agent that works in the human body and makes the various function of the body possible. Since the stress is a main hurdle to the performance of sports men it shall be given higher priority to be treated. Numerous physiological effects have been reported due to meditation and pranayama. Lowering the heart beat rate and metabolism, as well as respiration and blood pressure. Also, the meditators significantly improve in the $50 \mathrm{~m}$ dash, standing broad jump and in an agility test. Since it does not require any costly instrument, simple in nature, it can adapt to any field to get rid of stress. 